\title{
KRAS NM_004985.3:C.35_36delGTinsAC
}

National Cancer Institute

\section{Source}

National Cancer Institute. KRAS NM 004985.3:C.35 36delGTinsAC. NCI Thesaurus. Code C98371.

A complex substitution where the nucleotide sequence at positions 35 through 36 of the coding sequence of the KRAS gene has changed from guanine-thymine to adeninecytosine. 